\title{
Description of the late- or last-instar larva of Ischyomius Chevrolat, with comments on the family placement of the genus (Coleoptera: Tenebrionoidea: Pythidae)
}

\author{
Darren A. Pollock ${ }^{1} \&$ Jim McClarin²
}

\author{
1 Eastern New Mexico University (ENMU). Portales, New Mexico, United States. \\ ORCID: http://orcid.org/0000-0002-8709-0269. E-mail: darren.pollock@enmu.edu (corresponding author) \\ 2 Pontificia Universidad Católica del Ecuador (PUCE), Facultad de Ciencias Biologicas, Museo de Zoología (QCAZ), Sección de Invertebrados. \\ Quito, Pichincha, Ecuador. ORCID: http://orcid.org/0000-0003-1409-5322. E-mail:jimmcclarin@hotmail.com
}

\begin{abstract}
Study of recently collected larvae of two species of /schyomius Chevrolat, 1871 from Napo and Pichincha, Ecuador, tentatively identified as I. denticollis Champion, 1916 and I. singularis Chevrolat, 1871 confirm the classification of the genus Ischyomius within the family Pythidae. Salient larval characters which solidify this placement are: 5 stemmata arranged into an anterior column of 3 and posterior column of 2, parabasal ridges along anterior margins of abdominal tergites, prominent urogomphi with inner urogomphal teeth and various dorsal tubercles, and transverse row of dentiform asperities along anterior margin of sternite 9 . Important features of the larva are illustrated with photographs. A key to larvae of world genera of Pythidae is provided as well as natural history information on Ischyomius.
\end{abstract}

Key-Words. Immatures; Neotropical; Classification; Zingiberales; Ecuador; Venezuela.

\section{INTRODUCTION}

The Neotropical genus Ischyomius Chevrolat, 1878 currently contains eight species, encompassing a geographical range from Costa Rica in the north, to Bolivia in the south (Pollock, 1998, 2007, 2009). As with many other relatively obscure taxa of Tenebrionoidea, Ischyomius has had an unstable position within the classification of the tenebrionoid Coleoptera; it was placed in various families at different times, including Tenebrionidae, Melandryidae, Tetratomidae, and Trictenotomidae (Pollock, 2010). Placement of Ischyomius in Pythidae was first suggested by Lawrence (1982), who offered no detailed supporting evidence for this placement. In their treatment of beetle classification, Lawrence \& Newton (1995) placed Ischyomius as Pythidae, incertae sedis. As mentioned by Pollock \& Lawrence (1995: 467), "an additional three genera, Ischyomius, Trimitomerus and Osphyoplesius, should be placed there [Pythidae] tentatively, pending more detailed morphological studies and/or the discovery of the immature stages". This statement was repeated by Pollock (1998), as Ischyomius historically has been somewhat enigmatic taxonomically.

In a revision of the genus, Pollock (1998) provided evidence from various adult structural features that Ischyomius is closely related to genera already recognized as Pythidae. It was stated that discovery of the immature stages of a species of Ischyomius would be of great value, and would either corroborate or refute this adult-based family placement. Subsequent to Pollock (1998), larvae of Ischyomius became available and though not formally described, Pollock (2010) mentioned that features of the head, legs, and urogomphal plate were very similar to larvae of Pytho Latreille and supported placement of Ischyomius in Pythidae. More recently, important larval material of Ischyomius (with adults of I. denticollis Champion, 1916 and I. singularis Chevrolat, 1878) was collected by the second author in Napo and Pichincha Provinces, Ecuador.

Despite the lack of a publication of an actual larval description, Ischyomius has been placed in Pythidae in some recent publications (e.g., Lawrence et al., 2011; Pollock, 2018). The description of the mature larva of Ischyomius (either I. denticollis or I. singularis) removes any remaining doubt as to the family placement of the genus. The purpose of the present paper is to describe and illustrate the larva of Ischyomius, provide an updated key to larvae of world genera of Pythidae (originally in Pollock \& Lawrence, 1995), and comment on classification of the family. 


\section{MATERIAL AND METHODS}

This study was based on 14 medium-large larvae and 13 adults of Ischyomius (I. singularis and I. denticollis) collected in association with these larvae. Details are provided below in "Material examined". One larva was macerated in cold $\mathrm{KOH}$ before mouthparts were dissected from it. Photographs were taken of specimens in 70\% isopropanol with a Zeiss Discovery V20 stereoscope, acquired with ZEN 2.3 Lite and stacked using CombineZP (Alan Hadley).

Though no larvae were reared to adult or DNA matched to absolutely confirm the association presumed in this paper, we are confident that the larvae described herein are those of Ischyomius because of multiple co-occurrences with adults. At one site ("km 36, Rte 20, Pichincha, Ecuador"), adults of both I. denticollis and $I$. singularis were collected in addition to larvae representing two species (especially notable in their different urogomphi). The relative size of both adults and larvae, I. denticollis being larger (Pollock, 1998), led the authors to think that the larger of the two larvae is likely I. denticollis and the smaller I. singularis. However, a species not represented by adults cannot yet be ruled out in either case. Two of the vials from the Pichincha site contain adults of only I. denticollis and only the larger of the two species of larvae. These collections were made at a slightly higher elevation and approximately $0.5 \mathrm{~km}$ away from the other locality where a mixture of both species was collected. The separation of the two sites further suggests an association of the large larval type from the uphill sites with the adult of $I$. denticollis. In the case of the Napo site, only the smaller species of larvae was collected along with I. singularis adults, an additional reason to suppose that our larval association is valid. This will be confirmed or refuted when/if larvae are reared to adults or matched by DNA profiles.

Adults of one other Ischyomius species, I. bicolor Champion, are known from Ecuador. The Museum of Zoology - Invertebrates Section (QCAZ-I) of the Pontifical Catholic University of Ecuador, to which the Ecuador material will be returned, contains specimens of I. bicolor from the Yasuni National Park, ca. 200 m elevation. A search is planned for its yet undescribed larvae.

Terminology used in the description follows that of Lawrence (1991); the format of the description follows (as closely as possible) that of the larva of Anaplopus tuberculatus Blackburn (Pollock \& Lawrence, 1995) for ease of comparison.

\section{RESULTS}

\section{Mature larva of Ischyomius \\ (Figs. 1-17)}

Material examined: Ecuador, Napo, Rt. E20 near the Comedor Susanita and Cabaña Cascada Hollín, Lat. -0.695175, Lon. -77.731352, 1,100 m, 04.vi.2016, J. McClarin, ex dead but still moist petiole of ba- nana [3 adults of $I$. singularis and 3 medium-large larvae]; Pichincha, Rta. 20, km 36, lat. -0.44222222 , Ion. -78.74611111, 2,050 m, 13.xi.2016, J. McClarin, ex dead but still moist petiole of Heliconia [2 adults of $I$. denticollis, 3 adults of $I$. singularis, and 1 medium larva]; same locality, 14.xi.2016, J. McClarin, ex. Heliconia [2 adults of I. singularis and 7 medium to large larvae]; same locality, 2,050 m, 20.xi.2016, J. McClarin, ex. Heliconia [adult of $I$. denticollis and 2 large larvae]. VENEZUELA, Aragua, P.N. Henri Pittier, Rancho Grande [10.34861, -67.68444], 1,100 m, 27.iii.2004, H. Escalona, on dry banana leaves [2 adults of $I$. singularis and 1 medium larva].

Description: Body (Fig. 1) elongate, parallel-sided, slightly dorsoventrally flattened, light yellow, very slightly darker on head; labrum, antennae, tergite 9, apices of tubercles and asperities dark red-brown; setae slender, elongate, sparsely positioned over body surface, with serially repeated pattern on abdominal segments 1-8.

Head: Prognathous, exserted, with lateral edges slightly and evenly rounded (Fig. 2); epicranial suture with lyriform frontal arms contiguous at base, extending to just behind antennal insertions; epicranial stem and endocarinae absent. Stemmata 5, with anterior and posterior columns of 3 and 2 respectively (Fig. 3). Setation very sparse, with only 4 elongate setae in the following positions: dorsal, posterior of antennae at about $1 / 2$ length of head; lateral, just posterior of stemmata; ventral, just posterior of antennal fossa; ventral, just lateral of hypostomal ridge at level of submentum. Antennae (Figs. 3-4) prominent, 3-segmented; antennomere length ratios of scape, pedicel and flagellum approximately 5:4:2.5; sensorium subconical, relatively elongate, ventrally placed on pedicel, less than $0.5 \times$ length flagellum; setae absent from scape; pedicel with only a few short setae, apical only; flagellum with one relatively elongate seta apically, and several shorter setae subapically.

Mouthparts: Hypostomal ridges present; hypostomal rods short, somewhat divergent posteriorly (Fig. 4); ventral epicranial ridges absent; labrum (Fig. 2) symmetrical, anterior margin evenly arcuate, with several stout marginal setae; epipharynx (Fig. 5) with several stout, marginal setae; base with distinct cibarial plates. Mandibles (Figs. 6-11) heavily sclerotized, slightly asymmetrical; both mandibles bi- or tridentate apically, with 3-4 smaller subapical teeth of various sizes along dorsal inner margin of mandibles; molae distinct and subequal in size on both mandibles, surface consisting of narrowly spaced transverse ridges; left mola with distinct distal tooth, armed ventrally with several blunt teeth; right molar tooth smaller than left, without distinct teeth along ventral surface; dorsal surface of both mandibles with rows of microtrichia, developed into larger brush of setae near base of molar tooth (Figs. 10-11). Maxillae with blunt mala, slightly cleft apically, with row of elongate setae/spines along distal margin; uncus distinct, with 3 subequally sized, small rounded teeth (Fig. 5); maxillary articulating area distinct; maxillary palpi distinct, 3-seg- 
mented, lengths of palpomeres subequal; diameters decreasing from $1^{\text {st }}$ to $3^{\text {rd }}$ palpomere; palpi without setae except for single dorsal seta on palpomere 2, near apex. Labium (Figs. 4-5) with submentum trapezoidal, slightly longer than wide; mentum longer than wide, widest near anterior margin; prementum short, rectangular; labial palps 2-segmented, short, very widely separated, palpomeres subequal in length, but 1 distinctly wider than 2; ligula broad, subquadrate, with very slightly arcuate anterior margin, without setae.

Thorax: Cervicosternum divided into 3 separate plates, central plate distinctly narrower than the 2 laterals. Prothorax (Fig. 2) transverse, slightly narrower and distinctly longer than meso- or metathorax, without parabasal ridge along anterior margin; prothoracic setae as follows: pair at anterolateral corner, single seta at posterolateral corner, single seta anteriorly halfway between midline and lateral margins; meso- and metathorax subequal in size, with distinct parabasal ridges (Fig. 2); meso- and metathoracic setation similar: single seta at anterolateral corner, pair of setae at posterolateral corner; mesothoracic spiracle large, annular-biforous, vertically elliptical, with 6 very small dorsal accessory chambers; spiracular laterotergite slightly produced. Legs (Figs. 1, 3, 12-13) well developed, short; anterior face of coxae, trochanter and femur with field of short, stout, peg-like setae (Fig. 12); tarsungulus short, with single, very stout spine ventrally.

Abdomen: Tergites 1-8 subequal in length, but gradually increasing in length from anterior to posterior segments; anterior margin of tergites 1-9 with distinct parabasal ridges (Fig. 17), slightly thickened at midline, extended posteriorly along side of tergites just dorsal of spiracles, traceable to near midlength of tergites; abdominal spiracles oval, annular-biforous, peritreme subelliptical with 3-4 very small dorsal accessory chambers;

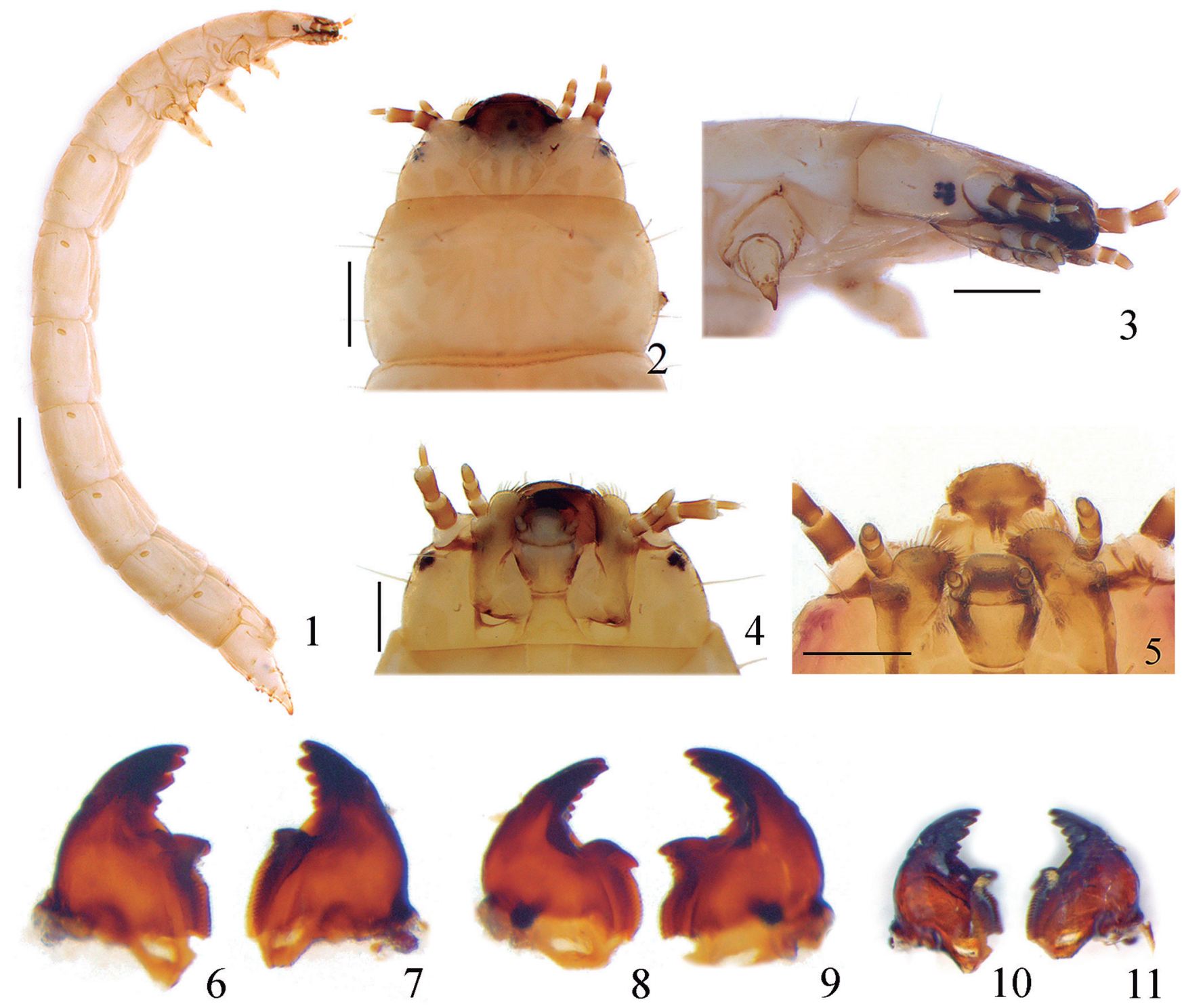

Figures 1-11. Ischyomius sp. larva: (1) habitus lateral; $(2,4)$ head (dorsal, ventral); (3) head and prothorax (lateral); (5) mouthparts, ventral; (6-11) mandibles: (6-7) left and right, dorsal; (8-9) right and left, ventral; (10-11) left and right dorsal, showing brush of microtrichia near molar teeth. Scale bars $=0.5 \mathrm{~mm}$, except Fig. $1=1 \mathrm{~mm}$. 

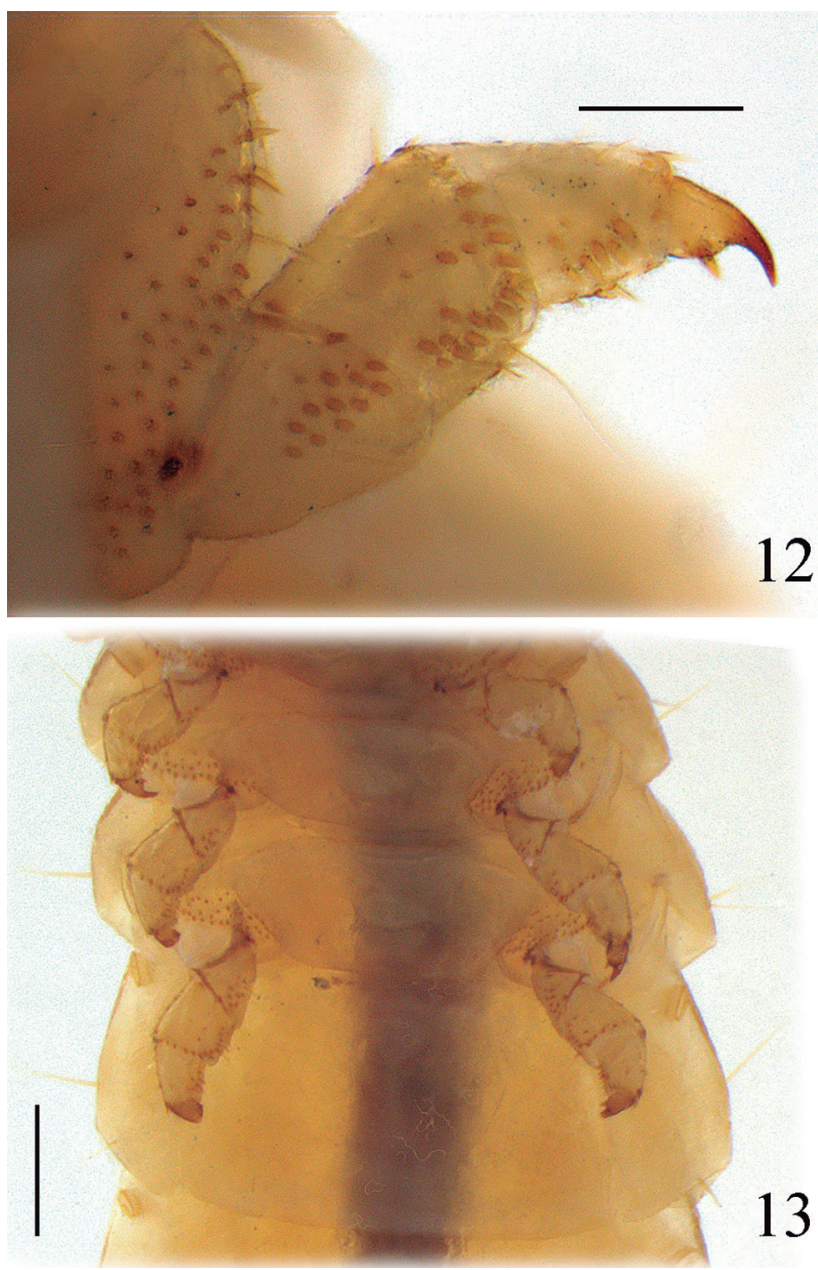

Figures 12-13. Ischyomius sp. larva: (12) anterior face of hind leg; (13) thorax and first abdominal segment, ventral. Scale bars $=0.25$ and 0.5 respectively.

tergite 9 slightly narrower than 8 , forming urogomphal plate; urogomphi (Figs. 14-16) distinct, relatively stout, outer margins convergent posteriorly, apices slightly upturned; inner margin of each urogomphus with two teeth (Figs. 15-16), one basally and one approximately $2 / 3$ length towards apex; in most specimens, distal tooth at least slightly larger than basal tooth; some specimens with basal urogomphal tooth very short; urogomphal pit and lip absent; tergite 9 with darkly pigmented tu- bercles of various sizes, in some specimens forming a transverse row of 3-4 tubercles either between urogomphal bases and basal urogomphal tooth (Fig. 15) or just anterior of urogomphal bases; several elongate setae present basally on tergite 9 , and laterally on urogomphi; tergite 9 extended ventrally, surrounding sternite 9 and anus (Fig. 16); asperities present along anterior margin of sternite 9, forming two slightly arcuate rows of 14-18 asperities each (Fig. 16), outermost asperity larger than others.

\section{Natural history and collection notes}

Pollock (2018) provided a summary of information on the natural history of Ischyomius adults and larvae, based in large part upon work done by the second author. These insects seem to be associated with a restricted group of plant species within the monocots (e.g., Musa, Strelitzia, and Heliconia), specifically within Order Zingiberales. Label data from adult specimens also suggest a possible association with palms (Arecaceae). Additional information is presented below, giving greater detail on the collection and habitat of Ischyomius in Ecuador.

In addition to furnishing the specimens on which the genus description is based, the collections in Ecuador provided valuable information on the host plants for Ischyomius. These beetles seem to be restricted to the dead and fermenting petioles of several families within the monocot order Zingiberales, especially the genera Musa L. and Heliconia L. (Pollock, 2018). The second author has since found an adult of $I$. denticollis in the axils of a Renealmia plant (also in Zingiberales) where the leaf was dead and the stem fermenting, leading to speculation that eggs might be deposited there also.

Ischyomius larvae are not subcortical in dead trees as in most other Pythidae but are found inside fermenting, fleshy petioles or central leaf veins of Zingiberales. Adults of at least two Ischyomius species have been found hiding between the folded halves of dead Zingiberales leaves, usually next to the large, still-moist, central vein of recently dead leaves. Leaves that are shaded much of the day seem to be preferred by the beetles over more

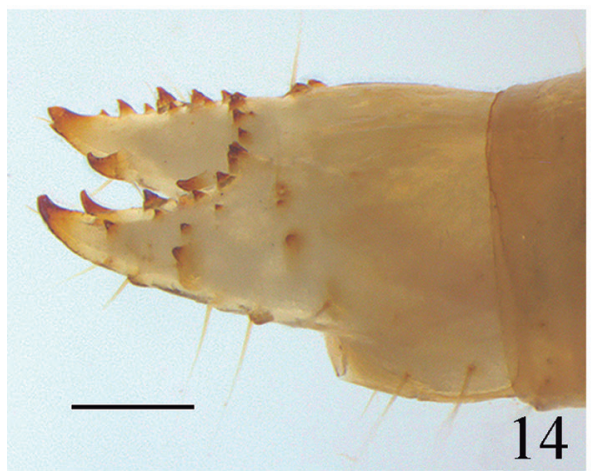

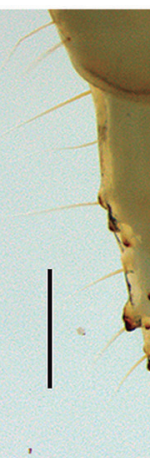

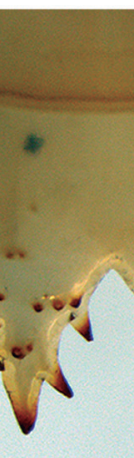

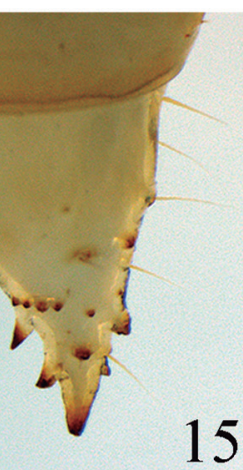

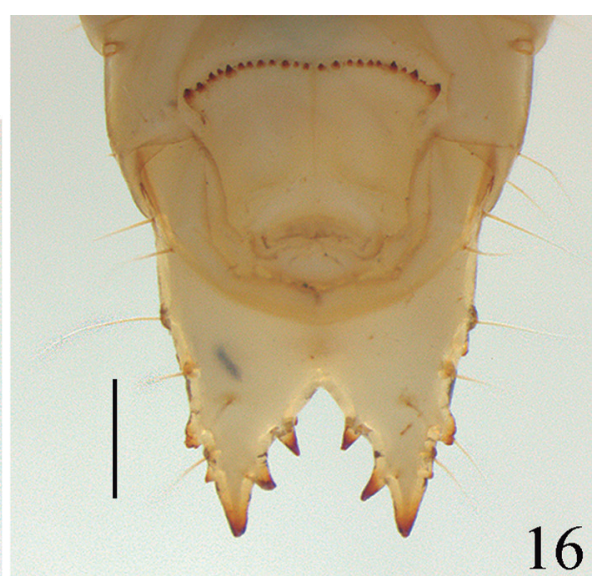

Figures 14-16. Ischyomius sp. larva: (14-15) urogomphal plate (dorsolateral, dorsal); (16) urogomphal plate and segment X (ventral). Scale bars =0.5 mm. 


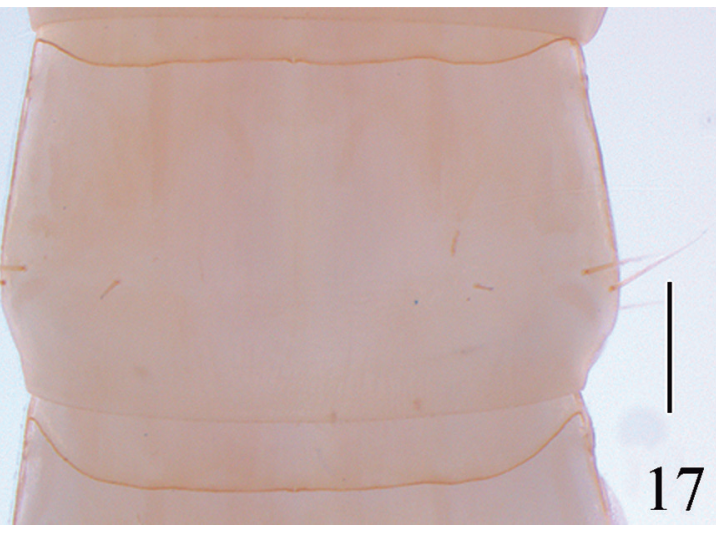

Figure 17. Ischyomius sp. larva: abdominal tergite III. Scale bar $=0.5 \mathrm{~mm}$.

exposed leaves. The second author's method of collecting adult Ischyomius and other Coleoptera from the same microhabitat has evolved from simply opening dead Zingiberales leaves to look for beetles to now placing the still-attached leaves into a deep insect net before cutting the stem or central leaf vein, thereby reducing the number of escapees. Leaves are shaken inside the net before being opened and examined. Adult beetles that were frequently found sharing the same microhabitat as Ischyomius include the silvanid genera Euplatamus Sharp, Silvanops Grouvelle, and Telephanus Erichson, erotylids from tribes Langurini and Toramini, and endomychids from the genera Anidrytus Gerstaecker, Archipines Strohecker, Corynomalus Chevrolat, and Epopterus Chevrolat. Occasional members of the families Carabidae, Staphylinidae, Hydrophilidae, Tenebrionidae, Chrysomelidae, Cerambycidae, and Curculionidae and miscellaneous others were also found. Ischyomius larvae were sought by carefully slitting soft, fermenting petioles with a knife and opening them by hand. Adult cillaeine Nitidulidae have been found as well inside the dead petioles.

\section{DISCUSSION}

As mentioned above, the larvae of Ischyomius and their morphological features have appeared in the "material examined" sections of a few studies, despite the fact that they had not been formally described. For example, Lawrence et al. (2011) used 516 morphological features of both adults and larvae including Ischyomius chevrolati Champion 1916 (listed in family Pythidae in material examined) and Pytho niger Kirby 1837 to elucidate a phylogeny of the entire Coleoptera. The cladogram depicts Ischyomius as sister group to Pytho Latreille and together, these are a sister group to Elacatis Pascoe (presently within Salpingidae) (clade \#71). Several larval features of Ischyomius (and Pytho) were used to define these relationships: incisor edge of mandible with 2 or more subapical teeth (Figs. 6-11), vestiture of legs including at least some stout spines (Fig. 12), urogomphi with accessory processes (Figs. 15-16), and sternum IX with basal row of asperities (Fig. 16). Interestingly, the larger clade (\#50) that encompasses the group including Ischyomius comprises current members of Lymexylidae, Synchroidae, Oedemeridae, Pyrochroidae, Boridae and Mycteridae.

As a complement to the morphology-based paper by Lawrence et al. (2011), McKenna et al. (2015) used DNA sequence data from eight nuclear genes to elucidate relationships among the suborders and superfamilies of Coleoptera. In both Bayesian and Maximum Likelihood trees, Ischyomius and Pytho (the only exemplars of Pythidae used in this study) were recovered as sister groups, within a monophyletic cluster approximating the "Salpingid Group" of Watt (1987) and Pollock (1994). In both trees, Ischyomius + Pytho is a sister group to a monophylum consisting of three genera of Salpingidae, with Elacatis (Salpingidae) forming the sister group to these five genera.

Of the three genera mentioned by Pollock \& Lawrence (1995) as provisionally belonging to Pythidae, only Ischyomius has had its larval stage formally described. Larvae of Osphyoplesius Winkler and Trimitomerus Horn remain unknown and/or undescribed. As such, the key to genera of known pythid larvae in Pollock \& Lawrence (1995) requires expansion, as indicated below (note: the first two couplets in the original key separated out larvae of Boridae and Trictenotomidae and are not repeated here):

3. Dorsal part of tergite 9 with a more or less continuous transverse series of distinct, setigerous pregomphal tubercles (4 or more per side); urogomphal lip (lying below pit) variously protruding posteriorly; abdominal parabasal ridges, if present, with posteriorly projecting processes mesally.

- Dorsal part of tergite 9 without a continuous transverse series of setigerous pregomphal tubercles or protruding urogomphal lip; abdominal parabasal ridges without posteriorly projecting processes mesally.

4(3). Body somewhat dorsoventrally depressed; parabasal ridges present on abdominal tergites; pregomphal tubercles relatively small, not bifid apically. Pytho Latreille

- Body subcylindrical; parabasal ridges absent from abdominal tergites; pregomphal tubercles large, bifid apically ........... Priognathus LeConte

$5\left(3^{\prime}\right)$. Basal urogomphal tooth distinctly larger and longer than apical inner tooth; pregomphal tubercles relatively large, arranged in straight to slightly arcuate row of 2 groups of 3 (occasionally a larva with 4 on a single side), with short gap medially, tubercle row not extended posteriorly onto bases of urogomphi; base of tarsungulus with single seta, or entirely glabrous..

- Inner urogomphal teeth subequal in size or with apical tooth larger than basal; pregomphal tubercles smaller, not arranged in neat row of 2 groups of 3 , in some specimens extended posteriorly onto bases of urogomphi; base of tarsungulus with single stout spine.

Ischyomius Chevrolat

6. Basal urogomphal tooth bifid apically in most specimens; dorsum of tergite 9 without extensive punctulae; sternite 9 without apicolateral asperities; western North America ................................. Sphalma Horn

- Basal urogomphal tooth not bifid apically; dorsum of urogomphal plate with extensive punctulae; sternite 9 with 2 apicolateral asperities, in addition to basal row; eastern Australia 


\section{ACKNOWLEDGMENTS}

The authors thank Dr. Clifford Keil, Professor and Director (retired), Museum of Zoology-Invertebrates Section (QCAZ-I), School of Biological Sciences, Pontifical Catholic University of Ecuador, Quito, and Álvaro Barragán (QCAZ) for their help in obtaining study specimens on loan. The loan of specimens for this study was authorized by the Museum of Zoology - Invertebrate Section, Pontifical Catholic University of Ecuador, Quito, Ecuador (QCAZ). Insects from Ecuador were collected under the research and collecting permit, 002-16-IC-FAU-DNB/MA, issued to the Museum of Zoology-Invertebrates Section by the Ministerio de Ambiente of the government of Ecuador. We thank Sônia Casari and Gabriel Biffi for extending an invitation to contribute to this celebration of the career of Dr. Cleide Costa.

\section{REFERENCES}

Lawrence, J.F. 1982. Coleoptera. In: Parker, S.P. (Ed.). Synopsis and classification of living organisms. New York, McGraw Hill. p. 485-553.

Lawrence, J.F. 1991. Order Coleoptera (Introduction). In: Stehr, F.W. (Ed.). Immature Insects. Dubuque, Kendall/Hunt. v. 2, p. 144-298.

Lawrence, J.F. \& Newton Jr., A.F. 1995. Families and subfamilies of Coleoptera (with selected genera, notes, references and data on family-group names). In: Pakaluk, J. \& Ślipiński, A. (Eds.). Biology, phylogeny, and classification of Coleoptera. Papers Celebrating the $80^{\text {th }}$ Birthday of Roy A. Crowson. Warszawa, Muzeum i Instytut Zoologii PAN. p. 779-1092.

Lawrence, J.F.; Ślipiński, A.; Seago, A.E.; Thayer, M.K.; Newton, A.F. \& Marvaldi, A.E. 2011. Phylogeny of the Coleoptera based on morphological characters of adults and larvae. Annals of Zoology, Warszawa, 61: 1-217. DOI
McKenna, D.D.; Wild, A.L.; Kanda, K.; Bellamy, C.L.; Beutel, R.G.; Caterino, M.S.; Farnum, C.W.; Hawks, D.C.; Ivie, M.A.; Jameson, M.L.; Leschen, R.A.B.; Marvaldi, A.E.; McHugh, J.V.; Newton, A.F.; Robertson, J.A.; Thayer, M.K.; Whiting, M.F.; Lawrence, J.F.; Ślipiński, A.; Maddison, D.R. \& Farrell, B.D. 2015. The beetle tree of life reveals that Coleoptera survived endPermian mass extinction to diversify during the Cretaceous terrestrial revolution. Systematic Entomology, 40: 835-880.

Pollock, D.A. 1994. Systematic position of Pilipalpinae (Coleoptera: Tenebrionoidea) and composition of Pyrochroidae. The Canadian Entomologist, 126: 515-532.

Pollock, D.A. 1998. Revision of the Neotropical genus Ischyomius with a discussion on its systematic position (Insecta: Coleoptera: Tenebrionoidea: Pythidae). Annals of Carnegie Museum, 67(3): 245-264.

Pollock, D.A. 2007. A new species of Ischyomius Chevrolat (Coleoptera: Pythidae) from Costa Rica. Coleopterists Bulletin, 61(2): 277-280.

Pollock, D.A. 2009. A new species of Ischyomius from Venezuela (Coleoptera, Tenebrionoidea, Pythidae) with a revised key to world species. ZooKeys, 6: 69-74.

Pollock, D.A. 2010. Pythidae Solier, 1834. In: Leschen, R.A.B.; Beutel, R.G. \& Lawrence, J.F. (Eds.). Coleoptera, Beetles Vol. 2: Morphology and Systematics (Elateroidea, Bostrichiformia, Cucujiformia partim). De Gruyter, Berlin, 708-715.

Pollock, D.A. 2018. Beetles (Coleoptera) of Peru: a survey of the families. Pythidae Solier, 1834. Revista Peruana de Biología, 25(3): 321-324. D0I

Pollock, D.A. \& Lawrence, J.F. 1995. Review of Anaplopus Blackburn (Coleoptera: Pythidae), with comments on constituents and systematics of Pythidae. In: Pakaluk, J. \& Ślipiński, A. (Eds.). Biology, phylogeny, and classification of Coleoptera. Papers Celebrating the $80^{\text {th }}$ Birthday of Roy A. Crowson. Warszawa, Muzeum i Instytut Zoologii PAN. p. 449-472.

Watt, J.C. 1987. The family and subfamily classification and New Zealand genera of Pythidae and Scraptiidae (Coleoptera). Systematic Entomology, 12: $111-136$ 